\title{
Visceral adiposity index among young girls with PCOS and its association with phenotypes and metabolic risk
}

\author{
Beena Joshi $^{1}$, Tejal Lakhan ${ }^{2}$, Srabani Mukherjee ${ }^{3}$, Anushree Patil ${ }^{4 *}$, Sayeed Unisa ${ }^{5}$
}

\author{
${ }^{1}$ Department of Operational Research, ICMR-NIRRH, Mumbai, Maharashtra, India \\ ${ }^{2}$ Research Scholar, IIPS Mumbai, Maharashtra, India \\ ${ }^{3}$ Department of Molecular Endocrinology, NIRRH, Mumbai, Maharashtra, India \\ ${ }^{4}$ Department of Clinical Research, ICMR-NIRRH, Mumbai, Maharashtra, India \\ ${ }^{5}$ Department of Mathematical Demography and Statistics, IIPS Mumbai, Maharashtra, India
}

Received: 16 November 2017

Accepted: 18 December 2017

\section{*Correspondence:}

Dr. Anushree Patil,

E-mail: nirrhdor@yahoo.co.in

Copyright: (C) the author(s), publisher and licensee Medip Academy. This is an open-access article distributed under the terms of the Creative Commons Attribution Non-Commercial License, which permits unrestricted non-commercial use, distribution, and reproduction in any medium, provided the original work is properly cited.

\begin{abstract}
Background: Polycystic Ovarian Syndrome (PCOS) is a growing endocrine-metabolic disease in India. Visceral Adiposity Index (VAI) is a surrogate marker of visceral adipose dysfunction and can be used as a useful predictor of unhealthy PCOS phenotypes in low resource settings. No cut-off has been assessed among Indian population.

Methods: Secondary data from 106 diagnosed girls with PCOS and 121 controls was analysed to estimate (i) VAI and BMI among different phenotypes (ii) risk of metabolic disorders using VAI among different phenotypes of PCOS and (iii) compare the overall diagnostic performance (for metabolic syndrome) of VAI, BMI and waist circumference. Results: Majority of the girls in the sample considered for analysis were lean PCOS (61\%). Mean VAI among PCOS (3.02) was significantly higher than normal controls (2.81). Classic and Mild Phenotypes had high VAI. A unit increase in VAI score was found associated with 5.23 times higher risk of metabolic syndrome (AOR: 5.23, 95\% CI: 2.261-12.086). A higher VAI with cut off value of 2.73 could predict risk of metabolic syndrome among PCOS cases, unlike the cutoff among Caucassian population of 1.67. The cut-off for the non- obese group was even higher i.e. 2.81 .

Conclusions: Given that Indians are genetically more prone to have excess visceral fat the cut-offs for measuring adiposity also needs to be re-defined. The findings of this small sample throws light on the prevalence of visceral adiposity among lean girls with PCOS emphasizing the need to also screen them for metabolic syndrome, educate them about these complications and motivate them to practice healthy lifestyles.
\end{abstract}

Keywords: Adolescents, Body mass index, Metabolic syndrome, PCOS, Visceral Adiposity Index

\section{INTRODUCTION}

Obesity is a leading precursor of poor metabolic health and is an emerging problem in India. Body Mass Index (BMI) is commonly used parameter to label a person as underweight, normal, over weight and obese. It is now increasingly recognised that Asian Indians are sarcopenic i.e. they have more fat at a lower BMI compared with
Caucasians, less muscle and many times there is more visceral than subcutaneous adiposity. There is no clear understanding if it is genetic or environmental. It has been reported that for the same BMI the body fat percentage among Asians was 3-5\% points higher. ${ }^{1}$ High BMI is not necessarily an expression of cardiometabolic risk, given that there exists metabolically healthy obesity. $^{2}$ Waist circumference is a method used to 
measure central obesity and it was found to be more strongly associated with risk of diabetes compared to BMI. But the same results were not true when it was assessed for hypertension and dyslipidaemia. ${ }^{3}$ There is increasing evidence of fat deposition around visceral organs that adds on to the inflammatory state of the body at a younger age and increasing predisposition of individuals to non-communicable diseases. Metabolically unhealthy fat acts as an endocrine organ itself secreting numerous hormones and cytokines thereby playing an important role in body's metabolism and immune response.

A critical review of methods to measure visceral adiposity analysed that while MRI/CT scans generate the most accurate information about visceral fat they are not cost effective and increase exposure to radiation. ${ }^{4}$ The review summarised that surrogate measures such as BMI and Waist circumference although inexpensive have limitations to measure visceral fat as they have least accuracy. The authors recommended more studies that could help advance accuracy and provide predictive results. ${ }^{4}$

PCOS is an emerging chronic endocrine disorder where obesity observed among $50-80 \%$ of cases has been reported as a precursor as well as a risk factor in the development of metabolic syndrome. The odds of obesity in PCOS was found to be 1.95 (1.52-2.50)..$^{5-7}$ However lean PCOS is also a very common finding among Asians. In a recent study conducted among adolescents we found $70 \%$ of adolescents diagnosed with PCOS were nonobese. $^{8}$ They also had normal waist circumference. In such situation one wonders whether they could be eventually prone to develop Metabolic Syndrome.

In routine practice BMI and waist circumference do not give an idea about visceral adiposity. MRI and CT are now considered the gold standard for the quantitative evaluation of visceral and subcutaneous adipose tissue. Since these two methods are extremely expensive and complicated to perform, they cannot be recommended in routinely clinical practice. Eventually such patients often miss being advised healthy lifestyle and when advised it becomes very challenging to get them adhering to it.

Hence a simple clinical index for adipose tissue dysfunction known as Visceral Adiposity Index (VAI) comes handy. It is an empirical mathematical model, gender-specific, based on simple anthropometric (BMI and WC) and functional parameters [triglycerides (TG) and HDL cholesterol (HDL)] and indicative of fat distribution and function. ${ }^{5}$

\section{$\mathrm{VAI}($ females $)=[\mathrm{WC} / 36.58+(1.89 \times \mathrm{BMI})] \times[\mathrm{TG} / 0.81]$ $\times[1.52 / \mathrm{HDL}]$}

It is a useful indicator for evaluation of cardio-metabolic risk and has been recommended as a useful tool for early detection of cardiometabolic risk associated with PCOS before it develops into overt metabolic syndrome. ${ }^{7}$ Diverse studies have observed that a higher value of VAI is often associated with the increasing risk of cardiometabolic diseases among PCOS women. In general conditions, a VAI more than 2.53 indicates metabolically unhealthy fat. VAI of greater than 1.67 is considered for detecting risk of metabolic syndrome among PCOS women. ${ }^{9}$ However there is no data in Indian setting on the exact cut-offs to optimise the use of VAI as a predictor of metabolically unhealthy fat. This paper aims to assess the optimal cut-offs among adolescent PCOS cases using secondary data from a community based prevalence study.

\section{METHODS}

This paper pertains to analysis of a subset of data collected as part of a larger study assessing community based prevalence of PCOS as per Rotterdam criteria among girls aged 15-24 years in a selected ward of Mumbai, India during 2010-2011. Data of 106 PCOS and 121 non-PCOS cases was considered for secondary analysis as it had all the prerequisite variables required for calculating visceral adiposity index which included clinical, hormonal and biochemical parameters. BMI for Asian populations was used as reference where overweight considered if BMI was $>23$ and if obesity $>25 .{ }^{10}$ Waist circumference of less than $80 \mathrm{~cm}$ was considered as normal. NCEP ATP III definition of Metabolic syndrome was used as reference. ${ }^{11}$

\section{Statistical analysis}

Data was analyzed using SPSS software Version 19, (IBM Bangalore). Frequencies and percentages were used for categorical data. Mean and standard deviations were calculated for continuous variables. Bivariate analysis was carried out to investigate the relationship between dependent and independent variables.

It is accomplished by doing cross tabulation between a pair of independent and dependent variables. Mean values of controls $\pm 2 \mathrm{SD}$ are considered for reference. Chi-Square test is done for each pair to find out if there exists any association between them. The level of confidence and alpha values are prefixed with $95 \%$ and 0.05 , respectively.

A multivariate analysis using binary logistic regression was carried out to assess the relationship of a dependent variable with multiple variables simultaneously. Finally, a ROC analysis is carried out to compare the overall diagnostic performance of VAI, BMI and waist circumference.

\section{RESULTS}

Majority of the girls considered in the sample were aged 15-19 years $(66.5 \%)$. The mean per capita income was Rs. $2092 \pm 1920$. 
Table 1: Difference in endocrine and metabolic profiles between PCOS and Non PCOS cases.

\begin{tabular}{|c|c|c|c|}
\hline & \multirow{2}{*}{$\begin{array}{l}\text { Non-PCOS } \\
\mathbf{n}=\mathbf{1 2 1}\end{array}$} & \multirow{2}{*}{$\begin{array}{l}\text { PCOS } \\
\mathbf{n}=\mathbf{1 0 6}\end{array}$} & \multirow{2}{*}{$\begin{array}{l}\mathrm{p} \text { - } \\
\text { value }\end{array}$} \\
\hline & & & \\
\hline VAI (Mean) & $2.81 \pm 0.90$ & $3.02 \pm 1.15$ & $0.053 *$ \\
\hline BMI (Mean) & $21.06 \pm 4.46$ & $21.78 \pm 4.92$ & 0.892 \\
\hline $\begin{array}{l}\text { Waist } \\
\text { circumference } \\
(\mathrm{cm}) \text { (Mean) }\end{array}$ & $77.48 \pm 11.03$ & $79.26 \pm 12.77$ & 0.211 \\
\hline $\begin{array}{l}\text { FSH (mean+SD) } \\
\mathrm{mIU} / \mathrm{mL}\end{array}$ & $4.00 \pm 1.20$ & $3.8 \pm 1.1$ & 0.34 \\
\hline $\begin{array}{l}\mathrm{LH}(\text { mean+SD) } \\
\mathrm{mIU} / \mathrm{mL}\end{array}$ & $6.3 \pm 2.8$ & $8.4 \pm 6.1$ & $0.000 *$ \\
\hline $\begin{array}{l}\text { Testosterone } \\
\text { (Mean+SD) } \\
\text { ng/mL }\end{array}$ & $0.35 \pm 0.1$ & $0.45 \pm 0.19$ & $0.000 *$ \\
\hline $\begin{array}{l}\text { Fasting blood } \\
\text { sugar (mean+SD) } \\
\text { g/dL }\end{array}$ & $72.68 \pm 7.3$ & $71.3 \pm 6.1$ & 0.319 \\
\hline $\begin{array}{l}\text { 2-h post } 75 g \\
\text { glucose } \\
(\text { mean+SD) g/DL }\end{array}$ & $92.9 \pm 11.4$ & $91.8 \pm 10.9$ & 0.519 \\
\hline Insulin & $\mathrm{n}=108$ & $n=102$ & \\
\hline $\begin{array}{l}\text { (Mean+SD) } \\
\mathrm{mIU} / \mathrm{mL}\end{array}$ & $14.98 \pm 6.01$ & $16.24 \pm 6.7$ & 0.176 \\
\hline $\begin{array}{l}\text { SHBG } \\
(\text { mean+SD) } \\
\text { nmol/L }\end{array}$ & $56.7 \pm 27.8$ & $49.8 \pm 26.1$ & 0.518 \\
\hline HDL & $n=121$ & $n=106$ & \\
\hline $\begin{array}{l}(\mathrm{mean}+\mathrm{SD}) \\
\mathrm{mg} / \mathrm{dL}\end{array}$ & $45.4 \pm 10.3$ & $45.6 \pm 9.92$ & 0.223 \\
\hline Triglyceride & $n=121$ & $n=106$ & \\
\hline $\begin{array}{l}\text { (mean+SD) } \\
\mathrm{mg} / \mathrm{dL}\end{array}$ & $67.9 \pm 17.9$ & $64.08 \pm 13.0$ & $.015^{*}$ \\
\hline
\end{tabular}

Clinical manifestations of irregular cycles were present in $42.3 \%$, hirsutism score of 8 and above was seen in $17.6 \%$ and mild to moderate acne was seen among $40 \%$ of the screened girls. The mean age at menarche was 13.07 years $( \pm 1.3$ years). Majority belonged to mild phenotypes $73.4 \%, 6.4 \%$ were frank phenotypes, another $6.4 \%$ classic and $13.8 \%$ were ovulatory phenotypes of PCOS. Majority of the sample under consideration was nonobese (61\%). The mean waist circumference was slightly higher among PCOS than controls but within normal range.

Statistically significant differences were observed in the hormonal parameters i.e. testosterone and LH levels between PCOS and controls. Although biochemical parameters were slightly higher among PCOS compared to the controls, but the difference was not statistically significant (Table 1).

The overall mean BMI was $21.39 \pm 4.68$ and mean VAI was $2.9 \pm 1.05$ for the entire sample under consideration. No difference was observed regarding mean BMI among PCOS and controls however mean VAI was found to be higher among PCOS than the controls (Table 1). Overall mean VAI values were significantly higher among nonobese and overweight/obese. It was also observed that the VAI did not differ across increasing BMI as even those that had normal body weight showed high VAI (Table 2).

Table 2: Difference in VAI among obese and nonobese girls.

\begin{tabular}{|c|c|c|c|}
\hline BMI & Mean & $\mathbf{N}$ & p-value \\
\hline Non-obese & $3.04 \pm 1.13$ & 138 & \multirow[t]{3}{*}{$0.046^{*}$} \\
\hline Obese/overweight & $2.74 \pm 0.88$ & 89 & \\
\hline Total & 2.92 & 227 & \\
\hline
\end{tabular}

$* \mathrm{P}$ value $<0.05$ statistically significant.

VAI was assessed across various phenotypes. All those who had classic phenotype showed abnormal VAI whereas the highest BMI was found among the ovulatory phenotypes (Table 3).

Table 3: Comparison of VAI and BMI with different PCOS phenotypes.

\begin{tabular}{|c|c|c|c|c|c|c|c|}
\hline & & & Mild & Frank & Classic & Ovulatory & Total \\
\hline \multirow{4}{*}{ VAI } & \multirow{2}{*}{ Normal } & $\mathrm{N}$ & 2 & 1 & 0 & 1 & 4 \\
\hline & & $\%$ & $2.60 \%$ & $14.30 \%$ & $0.00 \%$ & $7.10 \%$ & $3.80 \%$ \\
\hline & \multirow{2}{*}{ Abnormal } & $\mathrm{N}$ & 76 & 6 & 7 & 13 & 102 \\
\hline & & $\%$ & $97.40 \%$ & $85.70 \%$ & $100.00 \%$ & $92.90 \%$ & $96.20 \%$ \\
\hline \multirow{4}{*}{ BMI } & \multirow{2}{*}{ Non-Obese } & $\mathrm{N}$ & 55 & 3 & 6 & 5 & 69 \\
\hline & & $\%$ & $70.50 \%$ & $42.90 \%$ & $85.70 \%$ & $35.70 \%$ & $65.10 \%$ \\
\hline & \multirow{2}{*}{ Obese } & $\mathrm{N}$ & 23 & 4 & 1 & 9 & 37 \\
\hline & & $\%$ & $29.50 \%$ & $57.10 \%$ & $14.30 \%$ & $64.30 \%$ & $34.90 \%$ \\
\hline
\end{tabular}

Mean triglycerides, insulin, blood sugar fasting, and post $2 \mathrm{hrs} .75 \mathrm{gm}$ glucose and testosterone values were found to be higher among those who had higher VAI.
However, the differences were not statistically significant. Oligo menorrhea was also found to be reported more among those with high VAI (Table 4). 
Table 4: Biochemical parameters among normal and abnormal VAI cases.

\begin{tabular}{|llllllll|}
\hline \multirow{2}{*}{ VAI } & & Triglycerides & Insulin & Blood Sugar fasting & $\begin{array}{l}\text { Blood sugar 2 hours } \\
\text { post 75 gm glucose }\end{array}$ & Testosterone \\
\hline \multirow{2}{*}{ Normal } & Mean & 53.7250 & 16.2184 & 68.2500 & 86.3333 & 0.445 \\
\cline { 2 - 8 } & $\mathrm{N}$ & 4 & 4 & 4 & 3 & 4 \\
\multirow{2}{*}{ Abnormal } & Mean & 64.4882 & 16.7250 & 71.4041 & 92.0281 & 0.451 \\
\cline { 2 - 8 } & $\mathrm{N}$ & 102 & 98 & 97 & 89 & 102 & 0.452 \\
\multirow{2}{*}{ Total } & Mean & 64.0821 & 16.2382 & 71.2792 & 91.8424 & 106 \\
\hline
\end{tabular}

\section{Risk of metabolic syndrome using VAI}

Since the majority of the PCOS cases were lean they did not present with the requisite, three out of four criteria necessary to label them with metabolic syndrome. Therefore, cases having any 2 parameters above the $80^{\text {th }}$ percentile of normal values were used to calculate the probable risk. Using the Caucasian reference of VAI $>1.67$, a significant association was observed between metabolic syndrome and VAI after adjusting for other factors.

A unit increase in VAI score was associated with 5.31 times higher risk of metabolic syndrome (AOR: 5.23, 95\% CI: 2.261-12.086) (Table 5). For lean cases VAI the risk was 6.33 times higher (AOR: 6.33, 95\% CI: $2.157-$ 18.594) (Table 6).

Table 5: Risk of metabolic syndrome among PCOS cases.

\begin{tabular}{|lllll|}
\hline $\begin{array}{l}\text { Independent } \\
\text { Variables }\end{array}$ & Sig. & AOR & L5\% & C.I. \\
\hline VAI & $0.000 *$ & 5.311 & 2.31 & 12.21 \\
\hline BMI & 0.085 & 1.3 & 0.97 & 1.77 \\
\hline $\begin{array}{l}\text { Waist } \\
\text { circumference } \\
\text { (cm) }\end{array}$ & 0.815 & 1.01 & 0.96 & 1.74 \\
\hline $\begin{array}{l}\text { *p-value <0.05; } \\
\text { interval }\end{array}$ & AOR: Adjusted odd ratio; CI: Confidence \\
\hline
\end{tabular}

Table 6: Risk of metabolic syndrome among lean PCOS cases.

\begin{tabular}{|c|c|c|c|c|}
\hline \multirow{2}{*}{$\begin{array}{l}\text { Independent } \\
\text { variables }\end{array}$} & \multirow{2}{*}{ Sig. } & \multirow{2}{*}{$\begin{array}{l}\text { Adj. } \\
\text { OR }\end{array}$} & \multicolumn{2}{|c|}{ 95\% C.I. } \\
\hline & & & L.I & U.I \\
\hline VAI & $.001 *$ & 6.333 & 2.157 & 18.594 \\
\hline $\begin{array}{l}\text { Waist circumference } \\
(\mathrm{cm})\end{array}$ & .937 & .994 & .852 & 1.159 \\
\hline HOMA-IR & .581 & 1.297 & .515 & 3.270 \\
\hline
\end{tabular}

We then compared the overall diagnostic performance of VAI, BMI and waist circumference to identify visceral adiposity dysfunction among PCOS cases. It was observed that VAI had a better area under the curve followed by waist circumference and BMI (Figure 1).

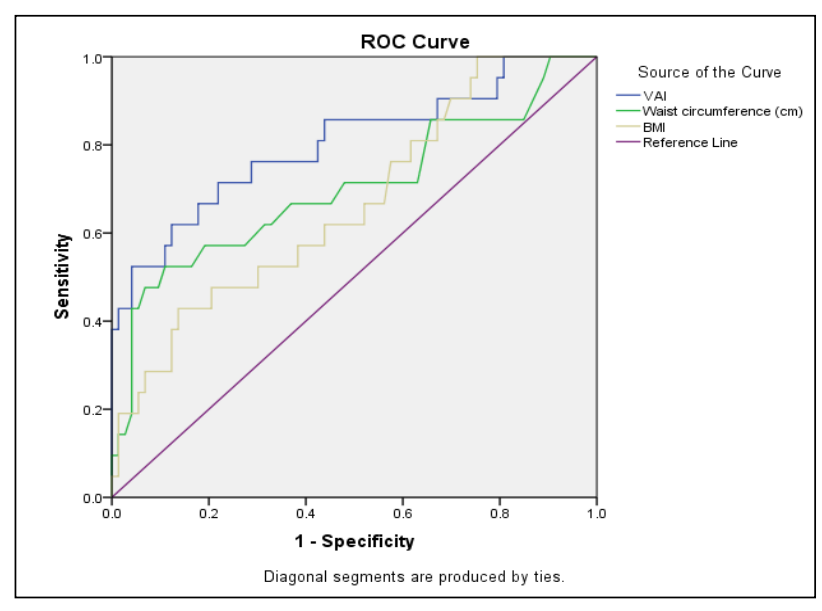

Figure 1: ROC curve: all PCOS cases.

A VAI with a cutoff of 1.67 had excellent sensitivity but very poor specificity (Table 7). Whereas a VAI with cutoff value of 2.73 has a sensitivity of 0.76 and specificity of 0.699 . Waist circumference featured as the second best to demonstrate good sensitivity and specificity followed by BMI.

Table 7: ROC analysis cut-off for metabolic disorders among PCOS cases and Lean PCOS cases.

\begin{tabular}{|c|c|c|c|}
\hline Diagnostic test & Cut-Off & Sensitivity & Specificity \\
\hline $\begin{array}{l}\text { VAI (literature } \\
\text { reference) }\end{array}$ & 1.67 & 1 & 0.06 \\
\hline VAI (study reference) & 2.73 & 0.76 & 0.699 \\
\hline BMI & 23.05 & 0.47 & 0.77 \\
\hline $\begin{array}{l}\text { Waist circumference } \\
(\mathrm{cm})\end{array}$ & 79.5 & 0.61 & 0.685 \\
\hline \multicolumn{4}{|c|}{$\begin{array}{l}\text { ROC analysis cut-off for metabolic disorders among lean } \\
\text { PCOS cases }\end{array}$} \\
\hline Diagnostic test & Cut-Off & Sensitivity & Specificity \\
\hline VAI (literature) & 1.67 & 1 & 0.02 \\
\hline VAI (study) & 2.81 & 0.82 & 0.71 \\
\hline BMI & 21.57 & 0.09 & 0.91 \\
\hline $\begin{array}{l}\text { Waist circumference } \\
(\mathrm{cm})\end{array}$ & 70.5 & 0.82 & 0.42 \\
\hline
\end{tabular}

Also among lean PCOS cases, VAI had a better area under the curve followed by waist circumference and BMI (Table 7 and Figure 2). VAI with a cutoff of 1.67 had excellent sensitivity but very poor specificity. 
Whereas a VAI with cut-off value of 2.81 showed a sensitivity of 0.82 and specificity of 0.71 . After VAI, waist circumference has good sensitivity and specificity followed by BMI.

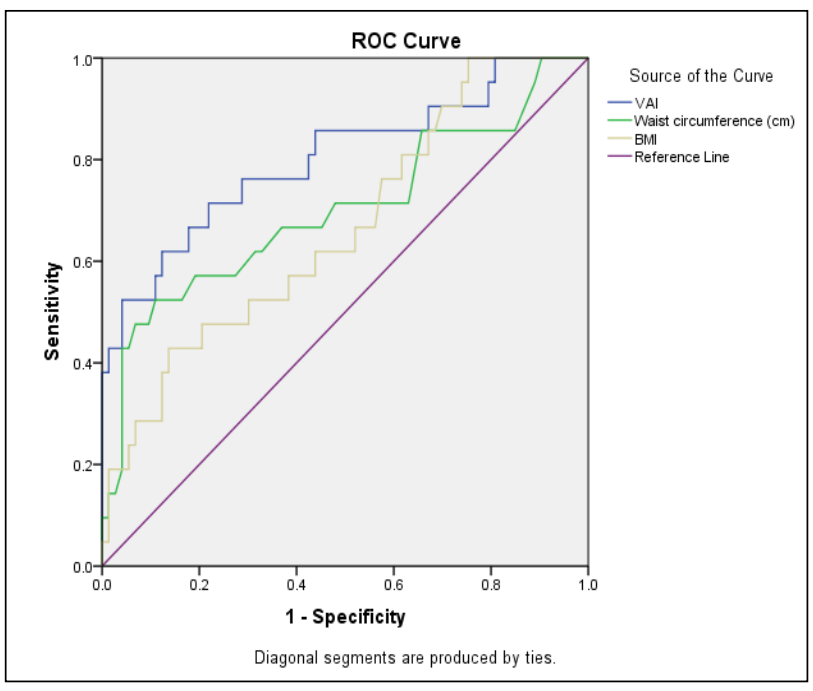

Figure 2: ROC curve (lean PCOS).

Through ROC analysis appropriate cut-offs were identified that were able to identify the risk of metabolic syndrome. Using these cut offs, it was observed that VAI was a better indicator than BMI or waist circumference. PCOS cases with abnormal VAI (>2.73) were found to be associated with 7.76 times higher risk of metabolic disorders as compared to cases among normal VAI (AOR: 7.757, 95\% CI: 2.041-29.48) (Table 8).

Table 8: Risk of metabolic disorders using VAI among PCOS cases- according to roc cut-off of 2.73 .

\begin{tabular}{|lllll|}
\hline $\begin{array}{l}\text { Independent } \\
\text { variables }\end{array}$ & Sig. & AOR & 95\% C.I. \\
\hline VAI & $0.003 *$ & 7.757 & 2.041 & U.I \\
\hline BMI & 0.517 & 1.083 & 0.851 & 1.377 \\
\hline $\begin{array}{l}\text { Waist circumference } \\
\text { (cm) }\end{array}$ & 0.219 & 1.055 & 0.969 & 1.149 \\
\hline HOMA-IR & 0.644 & 1.140 & 0.655 & 1.984 \\
\hline
\end{tabular}

*p-value $<0.05$; AOR: Adjusted odd ratio; CI: Confidence interval.

Table 9: Risk of metabolic disorders using VAI among lean PCOS cases: according to ROC cut-off of 2.81 .

\begin{tabular}{|lllll|}
\hline $\begin{array}{l}\text { Independent } \\
\text { variables }\end{array}$ & Sig. & AOR & 95\% C.I. & U.I \\
\hline VAI & $0.012 *$ & 9.425 & 1.629 & 54.527 \\
\hline $\begin{array}{l}\text { Waist circumference } \\
\text { (cm) }\end{array}$ & 0.189 & 1.086 & 0.960 & 1.228 \\
\hline HOMA-IR & 0.428 & 1.364 & 0.633 & 2.940 \\
\hline
\end{tabular}

Lean PCOS cases with VAI > 2.81 had 9.43 times higher risk of metabolic disorders than among normal VAI cases of PCOS (AOR: 9.43, 95\% CI: 1.63-54.53) (Table 9).

\section{DISCUSSION}

While prevalence of obesity has risen globally, the recent evidence showed that prevalence of moderate and severe underweight was highest in India, at $22.7 \%$ (16.7-29.6) among girls and $30.7 \%(23.5-38.0)$ among boys. ${ }^{12}$ The review concludes that there is a need for bridging the disconnect between policies that address underweight and overweight in children and adolescents to coherently address the large remaining underweight burden while curbing and reversing the rise in overweight and obesity. $^{12}$ Studies observing obesity paradox phenomenon, defined as normal weight obesity, have found that it was significantly associated with a higher risk of developing metabolic syndrome, cardio-metabolic dysfunction and with higher mortality. ${ }^{13}$

In a conflicting situation like this a serious thought has to go into why is India the capital for diabetes if majority of its population is not obese? is it only genetic? If yes is it also because of the predisposition to possess high amount of visceral fat? So how alert are the physicians in observing obesity beyond subcutaneous fat? Have we got enough know how, resources and accurate means to measure it? BMI, the most accepted cost-effective indicator to measure obesity tends to overestimate the problem of cardio-metabolic risk because of curvilinear and not a linear association with the body fat percentage in both men and women. ${ }^{14}$

BMI cannot differentiate between metabolically healthy fat and metabolically unhealthy fat. One seems to wonder if the machines which are widely used today are calibrated as per the profile of Indian populations.

The paper describes the importance of visceral adiposity in the context of PCOS which again is a precursor for metabolic syndrome. PCOS among adolescents is an emerging problem that needs careful assessment, timely intervention, and appropriate treatment. Obesity being a common manifestation in PCOS, lean/non-obese PCOS women/girls tend to be neglected and often not evaluated for their risk of developing metabolic syndrome.

These lean cases miss being counselled on importance of lifestyle changes or even if they are informed, it's extremely challenging to get them motivated to adopt to healthy lifestyle habits. Using a small sample, the paper explains that the cut-offs for VAI were higher than those mentioned in literature where most studies were done among Caucasian populations. This puts forth a proof of concept to re-think on the lines of BMI cut off which have now been separately established for Asians, is there is a need to develop separate cut-offs for measuring visceral adiposity too?

Visceral adiposity index is increased in patients with PCOS in concordance with the severity of anovulation, insulin resistance and inflammation. ${ }^{7}$ Another group also found a good correlation of VAI with hyperandrogenism, 
severity of anovulation, and liver function tests in women with polycystic ovary syndrome but there was no control group to match this. Hence the findings were not conclusive. $^{15}$

Since the sample size was very small, the results cannot be generalized. Studies with larger samples need to be undertaken to evaluate this proof of concept. Authentication of these results further needs to be done using gold standard MRI/CT Scan. India is a land of diversity and ethic variety. Cut-offs for one given population may not be suitable to another. We have wellbuilt tall genetic pool in the north compared to the north east and so also another very different sect of population in the south. A pooled estimate of these cut-offs could be derived to represent this part of the Indian subcontinent.

\section{CONCLUSION}

The application of this entire analysis is to alert the physicians to use some easy handy tools to diagnose metabolic risk early and prevent future morbidities among certain diseases like PCOS with proven severe future morbidities.

\section{ACKNOWLEDGMENTS}

Authors wish to acknowledge ICMR for funding the main prevalence study and NIRRH for all the infrastructure support. Authors are especially thankful to Dr. Smita Mahale, Director NIRRH and Dr. Sanjay Chauhan, Head, Department of Operational Research NIRRH for all the support and encouragement. Also, authors acknowledge the participants and the parents for their cooperation in participating in the main study from where this data was used.

\section{Funding: ICMR}

Conflict of interest: None declared

Ethical approval: The study was approved by the Institutional Ethics Committee

\section{REFERENCES}

1. Gallagher D, Heymsfield SB, Heo M, Jebb SA, Murgatroyd PR, Sakamoto Y. Healthy percentage body fat ranges: An approach for developing guidelines based on body mass index. Am J Clin Nutr. 2000;72:694-701.

2. Despre's JP. What is "metabolically healthy obesity"?: from epidemiology to pathophysiological insights. 2012;97(7):2283-5.

3. Huxley R, Mendis S, Zheleznyakov E, Reddy S, Chan J. Body mass index, waist circumference and waist: hip ratio as predictors of cardiovascular risk: a review of the literature. Eu J Clin Nutr. 2010;64(1):16-22.

4. Shuster A, Patlas M, Pinthus JH, Mourtzakis M. The clinical importance of visceral adiposity: critical review of methods for visceral adipose tissue analysis. $\mathrm{Br} \mathrm{J}$ Radiol. 2012;85(1009):1-10.

5. Amato MC, Giordano C. Visceral adiposity index: an indicator of adipose tissue dysfunction. Int $\mathrm{J}$ Endocrinol. 2014:2014.

6. Oh JY, Sung YA, Lee HJ. The visceral adiposity index as a predictor of insulin resistance in young women with polycystic ovary syndrome. Obesity. 2013;21(8):1690-4.

7. Amato MC, Verghi M, Galluzzo A, Giordano C. The oligomenorrhoic phenotypes of polycystic ovary syndrome are characterized by a high visceral adiposity index: a likely condition of cardiometabolic risk. Human Reprod. 2011;26(6):1486-94.

8. Joshi B, Mukherjee S, Patil A, Purandare A, Chauhan S, Vaidya R. A cross-sectional study of polycystic ovarian syndrome among adolescent and young girls in Mumbai, India. Indian $\mathrm{J}$ Endocrinol Metabol. 2014;18(3):317.

9. Amato MC, Guarnotta V, Forti D, Donatelli M, Dolcimascolo S, Giordano C. Metabolically healthy polycystic ovary syndrome (MH-PCOS) and metabolically unhealthy polycystic ovary syndrome (MU-PCOS): a comparative analysis of four simple methods useful for metabolic assessment. Human Reprod. 2013;28(7):1919-28.

10. Misra A, Chowbey P, Makkar BM, Vikram NK, WasirJS, Chadha D. Consensus statement for diagnosis of obesity, abdominal obesity and the metabolic syndrome for Asian Indians and recommendations for physical activity, medical and surgical management. J Assoc Physicians India 2009;57:163-70.

11. Grundy SM, Cleeman JI, Daniels SR, Donato KA, Eckel RH, Franklin BA, et al. Diagnosis and management of the metabolic syndrome. Circ. 2005;112(17):2735-52.

12. Abarca-Gómez L, Abdeen ZA, Hamid ZA, AbuRmeileh NM, Acosta-Cazares B, Acuin C, et al. Worldwide trends in body-mass index, underweight, overweight, and obesity from 1975 to 2016: a pooled analysis of 2416 population-based measurement studies in 128. 9 million children, adolescents, and adults. The Lancet. 2017;390(10113):2627-42.

13. Oliveros E, Somers VK, Sochor O, Goel K, LopezJimenez F. The concept of normal weight obesity. Progress in Cardiovascular Diseases. 2014;56(4):42633.

14. Hajer GR, van Haeften TW, Visseren FL. Adipose tissue dysfunction in obesity, diabetes, and vascular diseases. Eu Heart J. 2008;29(24):2959-71.

15. Androulakis II, Kandaraki E, Christakou C, Karachalios A, Marinakis E, Paterakis T, et al. Visceral adiposity index (VAI) is related to the severity of anovulation and other clinical features in women with polycystic ovary syndrome. Clin Endocrinol. 2014;81(3):426-31.

Cite this article as: Joshi B, Lakhan T, Mukherjee S, Patil A, Unisa S. Visceral adiposity index among young girls with PCOS and its association with phenotypes and metabolic risk. Int J Reprod Contracept Obstet Gynecol 2018;7:513-8. 